\title{
Comparative Study of Antimicrobial Activity of Betel leaf Extract and Antibiotics against Selected Bacterial Pathogens
}

\author{
Ayiman Abdullah Ali Almahdi* and Yashab Kumar \\ Department of Industrial Microbiology, SHUATS, Allahabad-211007, (U.P) India \\ *Corresponding author
}

Keywords

Extracts, antimicrobial activity, MDR, antibiotics susceptibility, MIC and MBC, E. coli,

B. cereus,

$P$. aeruginosa, and S. typhi

\section{Article Info}

Accepted:

15 February 2019

Available Online:

10 March 2019

\section{A B S T R A C T}

\section{Introduction}

In present time, drug resistance in microbes is a very serious problem. Hence, plant origin herbal medicines are considered as safe alternatives of synthetics drugs. There are varied methods of medicines like Ayurveda, homeopathy and Unani, which utilize plant materials for drug production. Currently, Aurveda considered as a vital system of medicine and governed the worldwide recognition and having non-toxic substances.
However, newly discovered non-antibiotics substances such as certain essential oils and their constituents chemicals have shown good fighting potential against drug resistant pathogens. Recently there has been a renewed interest in improving health and fitness through the use of more natural products. Herbs and spices are important part of the human diet. They have been used for thousands of years to enhance the flavor, color and aroma of food. In addition to boosting flavor, herbs and spices are also known for 
their preservative and medicinal value (deSouza, 2005) which forms one of the oldest sciences. Herbal medicines are also in great demand in the developed world for primary health care because of their efficacy, safety and lesser side effects. India despite its rich traditional knowledge, heritage of herbal medicines and large biodiversity has a dismal share of the world market due to export of crude extracts and drugs. And in this thesis the antimicrobial activity of Methanol extract of Betel leaves was evaluated against human pathogenic bacteria (both gram-positive and gram-negative), and antimicrobial activity of Acetone, Water, Methanol extract of Betel leaves was evaluated against human pathogenic bacteria both (gram-positive and gram-negative).

\section{Materials and Methods}

\section{Place of work}

The present study entitled "Comparative Study of Antimicrobial Activity of Betel leaf Extract and Antibiotics Against Selected Bacterial Pathogens" was conducted in the Post graduate laboratory, Department of Industrial Microbiology, Sam Higginbottom University of Agriculture, Technology and Sciences, PrayagRaj.

\section{Collection of sample}

The Betel leaf was collected from the local market of district PrayagRaj, dried at room temperature, ground in a pestle mortar, and stored in airtight container.

\section{Procurement of test bacteria}

Following Gram positive and Gram negative bacteria were collected from microbial culture collection bank (MCCB) of Department of Industrial Microbiology, SHUATS, Prayag Raj.
Bacillus cereus (MCCB006).

Pseudomonas aeruginosa (MCCB0035).

Escherichia coli (MCC0017).

Salmonella typhi (MCCB0023).

\section{Preparation of plant extracts}

Methanol, aqueous extract and acetone extract of Betel leaf was prepared as per the methods explained by Olayemi and Opaleye, (1999). Twenty gram of fine grounded powder of Betel leaf was dispensed into three beakers one containing $80 \mathrm{ml}$ of acetone, second containing $80 \mathrm{ml}$ of methanol and third containing $80 \mathrm{ml}$ of aqueous. These were soaked for 72 hours after which the solution was carefully filtered with muslin cloth into a sterilized conical flask of $100 \mathrm{ml}$ and the filtrates obtained was stored in the refrigerator at a temperature of $4^{\circ} \mathrm{C}$ until required.

\section{Antibacterial activity of betel leaf}

Antibacterial activity of Betel leaf extract was tested by using agar well diffusion method of Olayemi and Opaleye (1999) was used $0.5 \mathrm{ml}$ of each of the test organism from the 48 hourold culture was poured into different sterile Petri dishes. About $20 \mathrm{ml}$ of sterile media was aseptically poured into each dish. The dishes were gently rocked together for proper mixture and the nutrient agar. Afterwards, a well was dug in the plates with the aid of a sterilized cork borer of $6 \mathrm{~mm}$ diameter. Wells was bored on each plate; the well was filled by the $0.5 \mathrm{ml}$ methanol extracts, acetone extracts and aqueous extracts with the properly labelling of the wells. Was allowed to stand for one hour for proper diffusion and then incubated at $37^{\circ} \mathrm{C}$ for 24 hours. The sensitivity of the test organisms to Betel leaf was indicated by a clear zone of inhibition around the wells. The diameter of the clear zone (Zone of inhibition) was measured to the nearest millimetre using a transparent ruler. The test was performed in triplicates with control. 


\section{Antibiotic sensitivity test}

Disc diffusion assay was performed to detect the susceptibility of the test organisms against various antibiotics (Bauer et al, 1966). Melted and cooled Muller- Hinton media was poured in sterile petriplates and swabbed with $100 \mu 1$ of overnight culture of the test organism. Under aseptic conditions, antibiotic discs were placed on the surface of the inoculated plates with the help of sterile forceps following $24 \mathrm{~h}$ incubation at $37^{\circ} \mathrm{C}$ aerobically in upright position. Diameters of zone of inhibition around colony were measured in $\mathrm{mm}$ and results were interpreted according to the Clinical Laboratory Standards institute (CLSI) standards Wayne (2003).

\section{Minimum inhibitory Concentration (MIC)}

A three-fold serial dilution of the most potent extract was prepared in sterile nutrient broth to achieve concentration of $25.6,12.8,6.4,3.2$, $1.6,0.8,0.4,0.2,0.1,0.05 \mu \mathrm{l} / \mathrm{ml}$ in ten sterile tubes labeled 1 to 10 . To each test tube $1 \mathrm{ml}$ of actively growing bacterial cultures was inoculated. The inoculated culture tubes were incubated at $37^{\circ} \mathrm{C}$ for $24 \mathrm{~h}$. The lower concentration (highest dilution) that did not show any visible growth when compared with the control was considered as the minimum inhibitory concentration (MIC), Hoque, (2011).

\section{Minimum Bactericidal Concentration (MBC)}

Growth inhibitory assays were performed. For this purpose, inoculums size was adjusted to prepare a final colony number as $10^{10}$ colony forming units $(\mathrm{CFU} / \mathrm{ml})$ in sterile nutrient agar plates. These test and control cultures were kept at $37{ }^{\circ} \mathrm{C}$ for $24 \mathrm{~h}$. Comparison, both negatives and positive controls were set and bacterial colony number was counted. The least concentration at which no visible growth was obtained in agar plates were considered as
MBC. For evaluation of inhibition two parallel controls were set and bacterial growth was obtained in presence and absence of various quantities of extract.

\section{Statistical analysis}

The effect of various extracts obtained from individual Betel leaf was subjected to statistical analysis as per the method of two Way classification analysis of variance (ANOVA) table to judge the significant and non-significant effect of the data (Panse and Sukhatme, 1967).

\section{Results and Discussion}

\section{Antimicrobial activity of Betel Leaf}

The four test organisms were tested for their susceptibility towards the three extracts namely Methanolic extract of Betel, aqueous extract of Betel and acetone extract of Betel. Each test organism showed varied results when subjected to the three extracts.

\section{Antibacterial activity of Betel Leaf extracts against selected bacterial pathogens}

In the present study the extract of Betel were prepared in different solvents Methanol, Acetone, and distilled water. The Methanol extract of Betel was effective against all the test organisms with zone of inhibition from $29 \mathrm{~mm}$ to $40 \mathrm{~mm}$. The Methanol extract of Betel showed maximum activity against $S$. typhi giving an inhibition zone of $40 \mathrm{~mm}$. And exhibited least activity against $P$. aerug pnosa with zone of inhibition of $29 \mathrm{~mm}$. Methanol extract exhibited activity against B.cereus $36 \mathrm{~mm}$ and $E$. coli $32 \mathrm{~mm}$. The acetone extract of Betel was less effective than Methanol extract of Betel, and giving a zone of inhibition ranging from $27 \mathrm{~mm}$ to $34 \mathrm{~mm}$. The acetone extract of Betel showed maximum activity against S.typhi giving an inhibition zone of $34 \mathrm{~mm}$. Acetone extract of Betel 
exhibited least activity against $P$. aeruginosa zone of inhibition of $27 \mathrm{~mm}$. Acetone extract of Betel exhibited activity against $B$. cereus $32 \mathrm{~mm}$ and E. coli $30 \mathrm{~mm}$. The Distilled water extract of Betel was less effective than Methanol extract and acetone extract, and giving a zone of inhibition ranging from $18 \mathrm{~mm}$ to $27 \mathrm{~mm}$. The aqueous extract of Betel showed maximum activity against S.typhi giving an inhibition zone of $20 \mathrm{~mm}$. Aqueous extract exhibited least activity against $P$. aeruginosa zone of inhibition of $25 \mathrm{~mm}$. Activity against $B$. cereus and $E$. coli were $27 \mathrm{~mm}$ and $18 \mathrm{~mm}$ respectively. On analyzing the data statistically the result was found significant due to extract and non-significant due to organisms (Table 1; Fig. 1). In accordance with the present study several observation were made by different scientist and their co-worker. In study conducted by Kumar et al., (2013), it was reported that the Betel extract exhibited maximum inhibitory activity against $S$. typhi while moderate activity against $P$. aeruginosa, E. coli and $B$. cereus which was in agreement with the present study. Khan and Kumar et al., (2011) studied the efficacy of methanolic extracts of leaves of Piper betel for antibacterial properties against pathogenic bacteria namely Escherichia coli, Pseudomonas aeruginosa and Staphylococcus aureus. methanolic extracts were found to be more effective. In contrast to present study, the study conducted by Agarwal and Singh (2012) the Methanolic extracts of dried leaves of Piper betel were tested against pathogenic microorganisms such as Pseudomonas aeruginosa, Staphylococcus aureus and Escherichia coli. It is noteworthy that Pseudomonas aeruginosa was the more resistant to all the extracts tested. Comparative study was made on antimicrobial activity of some selected Indian medicinal plants using well diffusion method. Among the plant extracts tested, betel extracts showed maximum antimicrobial activity against all microbes. It is noteworthy that $E$. coli was resistant to all the extracts tested (Pandey et al., 2014). These results are due to differences in cell wall structure between Gram positive and Gram negative bacteria, with the Gram negative bacteria being more resistant because outer membrane acts as a barrier to many environmental substances, including antibiotic.

\section{Antibiotic susceptibility pattern of test bacteria}

In the present study, using the disc-diffusion method, four test organisms. E. coli, S. typhi, $B$. cereus, $P$. aeruginosa were tested for antibiotic susceptibility pattern. E. coli, $S$. typhi, B. cereus and $P$. aeruginosa were found to be resistant against Ampicillin, Rifampicin. Teicoplanin was found to be inhibiting the growth of $P$. aeruginosa, $S$. typhi, E. coli but B. cereus showed resistance toward it. All the four organisms were susceptible toward Ofloxacin, Ciprofloxacin, Norfloxacin, Kanamycin, Azithromycin, Tetracycline, and Gentamycin. Ampicillin was showed least effective on all antibiotics for four organisms E. coli, S. typhi, B. cereus, $P$. aeruginosa but Ciprofloxacin was effective for all four organisms viz., $E$. coli, S. typhi, B. cereus, P. aeruginosa (Table 2; Fig. 2, 3). Similar pattern of susceptibility has been reported by several workers for $E$. coli, S. typhi, B. cereus, P. aeruginosa, Shalini et al., (2011). In contrast to present study, Sangeetha et al., (2014) detected the current antibiotic resistance pattern of $E$. coli with a special reference to fluroquinolone resistance. Among 311 culture positive urine samples, 203 were $E$. coli. High resistance rate to Ampicillin (81.3\%), Co-trimoxazole $(83.3 \%)$ and low resistance rate to Nitrofurantoin (17\%) were noted for E. coli. In an another study Abdu and Kachallah, (2018) found Ampicillin was not the effective antibiotic for Uropathogenic E. coli (UPEC) isolates followed by Ciprofloxacin and Norfloxacin, 
however, the most effective antibiotic against the isolates was Nitrofurantoin followed by Chloramphenicol. Out of the four test organisms, E. coli, S. typhi and P. aeruginosa were found to be multidrug resistance. Multiple-drug resistance in microorganisms are due to the presence of plasmid DNA and several drug resistant genes in a single plasmid, or due to glycopeptides resistance, drug-specific MDR efflux pumps which are usually specified by chromosome, plasmidbone genes which confer resistance without the need for additional mutations opine to the multi-copy state of these genetic element or chromosomally encoded MDR pump genes that often occurs because of increased gene expression, which can take place as a consequence of regulatory mutations that, in certain instances, confer only low-level resistance to the host. Multidrug resistance via genes borne on conjugationally transmitted plasmids is among the best-known processes for bacteria adaptation, Jesonbabu et al., (2015).

\section{Determination of Minimum inhibitory Concentration (MIC) and Minimum Bactericidal Concentration (MBC)}

Further, using the macro-dilution broth method the most potent of the three extracts of Betel Leaf, i.e. Methanol extract was subjected to MIC determination against all the four organisms. The Methanol extract of Betel leaf was serially diluted to get a decreasing concentration 512 to $2 \mu \mathrm{l} / \mathrm{ml}$ of nutrient broth. Methanol extract when seeded with $25 \mu \mathrm{l} / \mathrm{ml}$ of the broth cultures, exhibited MIC at 0.2 $\mu \mathrm{l} / \mathrm{m}$ l for E. coli, $3.2 \mu \mathrm{l} / \mathrm{ml}$ for B. cereus, 12.8 $\mu \mathrm{l} / \mathrm{ml}$ for $P$. aeruginosa, $0.1 \mu \mathrm{l} / \mathrm{ml}$ for $S$. typhi (Table 3). For determination of Minimum Bactericidal Concentration (MBC), the tubes that were incubated for MIC were taken and from each concentration a loop full of test cultures were taken out and streaked on solidified nutrient agar. The least concentration at which no visible growth was observed in the Nutrient agar plates was considered as MBC. The exhibited MBC at $0.4 \mu \mathrm{l} / \mathrm{ml}$ for E. coli, $3.2 \mu \mathrm{l} / \mathrm{ml}$ for B. cereus, $12.8 \mu \mathrm{l} / \mathrm{ml}$ for $P$. aeruginosa, $0.2 \mu \mathrm{l} / \mathrm{ml}$ for S. typhi, (Table 4). In vitro studies in the investigation showed that Betel leaf extract exhibited inhibitory activity on all the microorganisms tested but their effectiveness varied. The data obtained in this study indicate the stronger activity of Betel leaf extract as it showed lower MIC on all the microorganisms tested (Table 3). In contrast to present study, Hoque et al., (2011) carried out screening of the Methanol extract of Betel leaf activity against some food borne pathogens. The Methanol extract of betel leaf showed the highest MIC values for E. coli (ATCC 25922). The inhibition produced by the extracts against particular organism depends upon various extrinsic and intrinsic parameters. Due to variable ability of diffusion in the nutrient broth medium, the antibacterial property may not demonstrate as visible density commensurate to its efficiency. Therefore MBC value has also been computed in the study. MBC is the lowest concentration of antibacterial substance required to produce a sterile culture. In contrast, Marina et al., (2007) conducted a study and found MBC for E.coli, S. aureus ranged from $20-80 \mu 1 / \mathrm{ml}$.

\section{Comparative analysis of Methanol extract} of Betel leaf and antibiotics

A comparative study was done between methanol extract of Betel leaf and antibiotics and Table 5 depicts a comparison between the antimicrobial activity of Methanol extract of Betel leaf and antibiotics against the test organisms. Majority of the bacteria selected for the study were multidrug resistant or showed a tendency to developing as MDR strains however the plant extracts prepared in methanol were effective in inhibiting the test organisms, analyzing the data statistically, 
figure 4 Comparative study of Methanol extract of Betel leaf and antibiotics. Majority of the test organisms viz., E. coli, S. typhi and $B$. cereus showed resistance towards antibiotics Ampicillin, Rifampicin, Vancomycin, Teicoplanin but they showed sensitivity to Methanol extracts of Betel leaf. Other studies have also reported similar observation where drug resistant bacterial strains have been found to be sensitive to plant extracts.

Table.1 Antimicrobial activity of Betel leaf extracts against selected bacterial pathogens

\begin{tabular}{|l|c|c|c|c|}
\hline & \multicolumn{4}{|c|}{ Test organisms showing Zone of inhibition(mm) } \\
\hline Betel leaf extracts & E. coli & S. typhi & P. aeruginosa & B. cereus \\
\hline Methanol extracts $(1 \mathrm{~mL})$ & $32 \mathrm{~mm}$ & $40 \mathrm{~mm}$ & $29 \mathrm{~mm}$ & $36 \mathrm{~mm}$ \\
\hline Acetone extracts $(1 \mathrm{~mL})$ & $30 \mathrm{~mm}$ & $34 \mathrm{~mm}$ & $27 \mathrm{~mm}$ & $32 \mathrm{~mm}$ \\
\hline Aqueous extracts $(1 \mathrm{~mL})$ & $18 \mathrm{~mm}$ & $20 \mathrm{~mm}$ & $25 \mathrm{~mm}$ & $27 \mathrm{~mm}$ \\
\hline
\end{tabular}

Due to organism: $\mathrm{F}_{(\mathrm{cal}) 5 \%}=1.58<\mathrm{F}_{\text {(tab)5\% }}=4.76, \mathrm{SE} \cdot \mathrm{d}=2.447, \mathrm{CD}$ at $5 \%=$ Not significant $(\mathrm{NS})$

Due to extracts: $\mathrm{F}_{(\mathrm{cal}) 5 \%}=10.18>\mathrm{F}_{(\mathrm{tab}) 5 \%}=5.14$, SE.d $=2.627, \mathrm{CD}$ at $5 \%=6.428(\mathrm{~S})$

Table.2 Antibiotic susceptibility profile of test organisms

\begin{tabular}{|l|c|c|c|c|c|}
\hline \multicolumn{1}{|c|}{ Antibiotic } & Disc $(\boldsymbol{\mu g})$ & $\boldsymbol{E}$. coli & S. typhi & P. aeruginosa & B. cereus \\
\hline Ampicillin & 10 & R & R & R & R \\
\hline Chloroamphenicol & 30 & I & S & R & I \\
\hline Rifampicin & 5 & R & R & R & R \\
\hline Gentamycin & 10 & I & I & S & S \\
\hline Tetracycline & 30 & I & I & S & I \\
\hline Ciprofloxacin & 5 & S & S & S & S \\
\hline Norfloxacin & 10 & S & S & S & S \\
\hline Kanamycin & 30 & I & I & S & S \\
\hline Azithromycin & 15 & S & S & S & S \\
\hline Ofloxacin & 5 & S & S & S & S \\
\hline Vancomycin & 30 & R & R & S & R \\
\hline Teicoplanin & 30 & S & S & S & R \\
\hline
\end{tabular}

$\mathrm{R}=$ Resistant, $\mathrm{I}$ = Intermediate, $\mathrm{S}=$ Sensitive

Table.3 MIC of Methanol extract of Betel Leaf

\begin{tabular}{|c|c|c|c|c|c|c|c|c|c|c|c|}
\hline Test organisms & \multicolumn{1}{|c|}{ Concentration of Methanol extract of Betel Leaf $(\mu \mathrm{l} / \mathrm{ml})$} \\
\cline { 2 - 14 } & 25.6 & 12.8 & 6.4 & 3.2 & 1.6 & 0.8 & 0.4 & 0.2 & 0.1 & 0.05 & MIC \\
\hline E.coli & - & - & - & - & - & - & - & - & + & + & 0.2 \\
\hline B.cereus & - & - & - & - & + & + & + & + & + & + & 3.2 \\
\hline P.aeruginosa & - & - & + & + & + & + & + & + & + & + & 12.8 \\
\hline S.typhi & - & - & - & - & - & - & - & - & - & + & 0.1 \\
\hline
\end{tabular}


Int.J.Curr.Microbiol.App.Sci (2019) 8(3): 2009-2019

Table.4 MBC of Methanol extract of Betel Leaf

\begin{tabular}{|c|c|c|c|c|c|c|c|c|c|c|c|}
\hline Test organisms & \multicolumn{10}{|c|}{ Concentration of Methanol extract of Betel Leaf $(\mu \mathrm{l} /) \mathrm{ml}$} \\
\cline { 2 - 14 } & 25.6 & 12.8 & 6.4 & 3.2 & 1.6 & 0.8 & 0.4 & 0.2 & 0.1 & 0.05 & $\mathrm{MBC}$ \\
\hline E.coli & - & - & - & - & - & - & - & + & + & + & 0.4 \\
\hline B.cereus & - & - & - & - & + & + & + & + & + & + & 3.2 \\
\hline P.aeruginosa & - & - & + & + & + & + & + & + & + & + & 12.8 \\
\hline S.typhi & - & - & - & - & - & - & - & - & + & + & 0.2 \\
\hline
\end{tabular}

Table.5 Comparative study of methanol extract of betel leaf and antibiotics

\begin{tabular}{|c|c|c|c|c|c|c|c|c|c|c|c|c|c|}
\hline \multirow{2}{*}{$\begin{array}{c}\text { Test } \\
\text { organisms }\end{array}$} & $\begin{array}{c}\text { Methanol } \\
\text { extract }(1 \mathrm{~mL})\end{array}$ & \multicolumn{12}{|c|}{$\begin{array}{c}\text { ANTIBIOTICS } \\
\text { ZONE OF INHIBITION(mm) }\end{array}$} \\
\hline & Betel leaf & $\begin{array}{c}\text { AMP } \\
10 \\
\mu \mathrm{g}\end{array}$ & $\begin{array}{c}\mathrm{C} \\
30 \\
\mu \mathrm{g}\end{array}$ & $\begin{array}{c}\text { RIF } \\
5 \\
\mu \mathrm{g}\end{array}$ & $\begin{array}{c}\mathrm{G} \\
10 \\
\mu \mathrm{g}\end{array}$ & $\begin{array}{c}\text { TET } \\
30 \\
\mathrm{Mg}\end{array}$ & $\begin{array}{c}\text { CIP } \\
5 \\
\mu \mathrm{g}\end{array}$ & $\begin{array}{c}\mathrm{NX} \\
10 \\
\mu \mathrm{g}\end{array}$ & $\begin{array}{l}\mathrm{K} \\
30 \\
\mu \mathrm{g}\end{array}$ & $\begin{array}{c}\text { AT } \\
15 \mu \mathrm{g}\end{array}$ & $\begin{array}{c}\mathrm{OF} \\
5 \\
\mu \mathrm{g}\end{array}$ & $\begin{array}{c}\text { VA } \\
30 \\
\mu \mathrm{g}\end{array}$ & $\begin{array}{c}\text { TEI } \\
30 \\
\mu \mathrm{g}\end{array}$ \\
\hline E.coli & 32 & 00 & 18 & 00 & 17 & 17 & 36 & 34 & 17 & 28 & 31 & 00 & 23 \\
\hline P.aeruginosa & 29 & 10 & 11 & 13 & 24 & 24 & 32 & 30 & 22 & 20 & 28 & 18 & 19 \\
\hline B.cereus & 36 & 00 & 13 & 00 & 21 & 18 & 27 & 24 & 18 & 11 & 22 & 13 & 00 \\
\hline S. typhi & 40 & 00 & 22 & 00 & 17 & 16 & 28 & 27 & 14 & 23 & 23 & 00 & 27 \\
\hline
\end{tabular}

AMP $=$ Ampicillin,$\quad \mathrm{C}=$ Chloramphenicol, $\quad$ RIF $=$ Rifampicin, $\mathrm{G}=$ Gentamycin, $\quad$ TET $=$ Tetracycline, $\mathrm{CIP}=$ Ciprofloxacin, $\mathrm{NX}=$ Norfloxacin, $\mathrm{K}=$ Kanamycin, $\mathrm{AT}=$ Azithromycin, $\mathrm{OF}=$ Ofloxacin, $\mathrm{VA}=$ Vancomycin,TEI=Teicoplanin

Fig.1 Antimicrobial activity of betel leaf extracts against selected bacterial pathogens

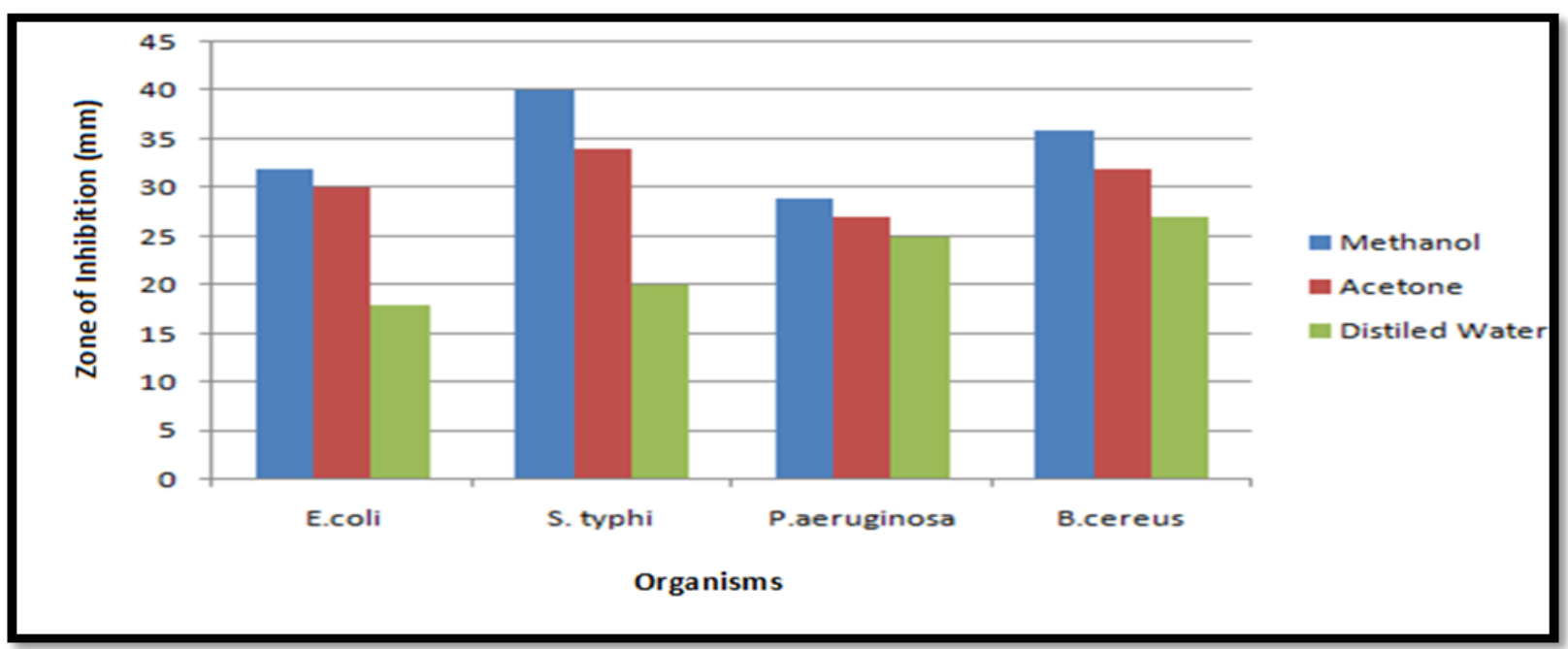


Fig.2 Antibiotics sensitivity of gram positive bacteria

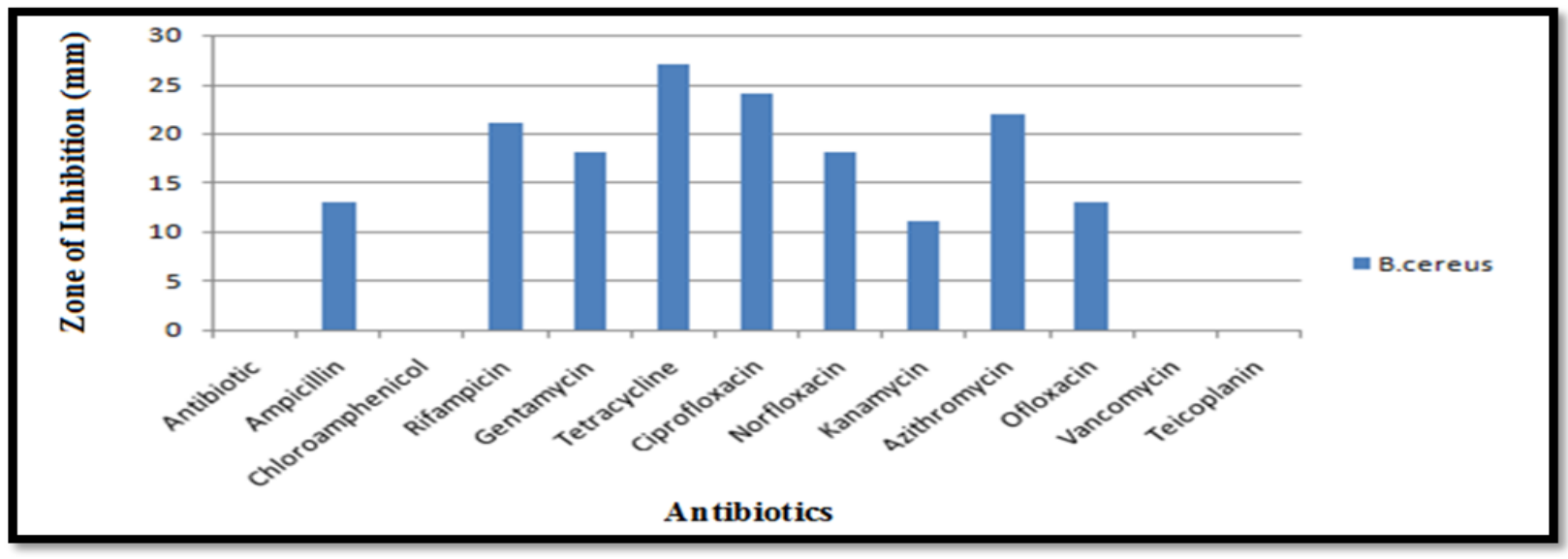

Fig.3 Antibiotics susceptibility test for gram negative organisms

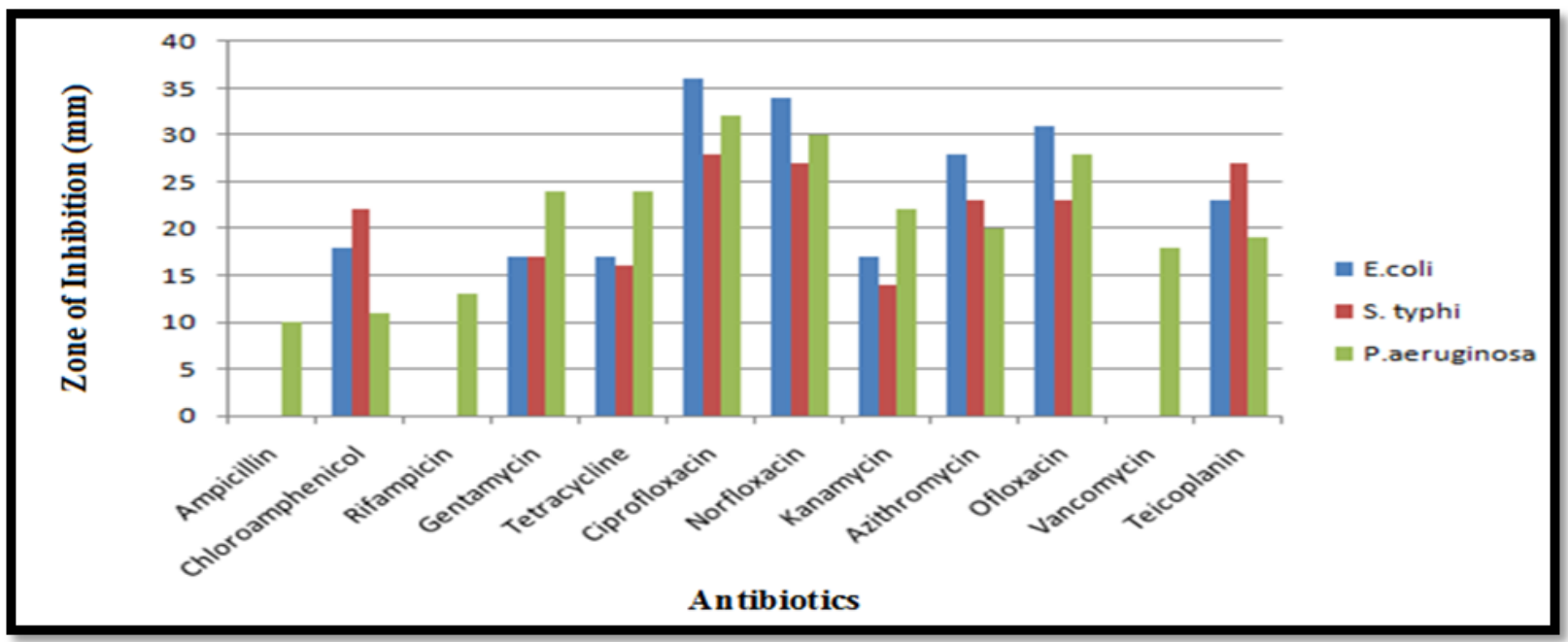

Fig.4 Comparative study of Methanol extract of Betel leaf and antibiotics

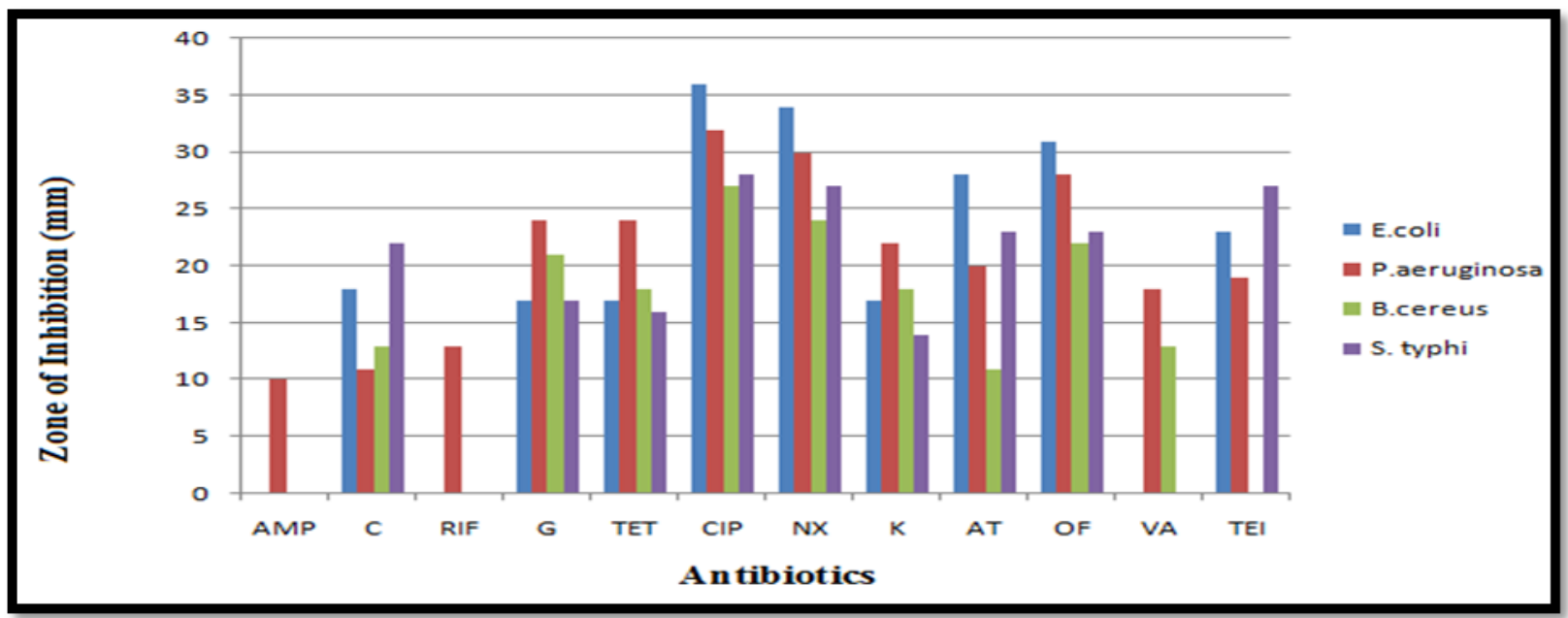


Summary and Conclusions are as follows:

Methanol extracts of Betel leaf showed higher diameter of Zone inhibition than Chloramphenicol, Gentamycin, Tetracycline, Ciprofloxacin, Norfloxacin, Kanamycin, Azithromycin, Ofloxacin, Vancomycin and Teicoplanin (Table 5; Fig. 4). In study conducted by Kumar et al., (2010) was reported that the Betel leaf extract exhibited maximum antimicrobial activity against $E$. coli was found similar to present on antibiotic resistant microorganisms has to be using new and natural antimicrobials studied by Khan and Kumar (2011). The resistance of tested bacteria to Betel leaf, due to thickness of the cell wall or to the permeability of the cell membrane or other cell and genetic factors. The variation of susceptibility of the tested microorganisms could be attributed to their intrinsic 9+properties that are related to the permeability of their cell surface to the extracts. Chakraborty and Shah (2011) also Observed the similar results in which Betel leaf extract was found to be more effective as compared to antibiotics.

The present study entitled "Comparative Study of Antimicrobial Activity of Betel leaf Extract and Antibiotics against Selected Bacterial Pathogens" has been carried out to find antibacterial activity of three different extracts against four test organisms viz., E.coli, S. typhi, P.aeruginosa and B.cereus using agar well-diffusion method. Four test organisms were tested for their antibiotic susceptibility towards different antibiotics. From the present study conducted, the following observations were made and conclusion drawn:

Methanol extract of Betel leaf was more effective against the test organisms then acetone extract and aqueous extract. S. typhi, was found most susceptible towards Methanol extract of Betel leaf followed by E.coli, P. aeruginosa and B.cereus.
Antibiotic susceptibility pattern revealed that among 4 tests organisms, Ciprofloxacin was found most effective whereas Ampicillin was found least effective. E.coli was found resistant against Ampicillin, Rifampicin, Vancomycin, intermediate against Gentamycin, Tetracycline, Kanamycin, and Chloramphenicol, and found susceptible against Ciprofloxacin, Norfloxacin, Ofloxacin, Azithromycin, and Teicoplanin. $S$. typhi also was found resistant against Ampicillin, Rifampicin, Vancomycin, intermediate against Gentamycin, Tetracycline, Kanamycin, and found susceptible against Chloroamphenicol, Ciprofloxacin, Norfloxacin, Azithromycin, Ofloxacin and Teicoplanin. P.aeruginosa was found resistant against for Ampicillin, Chloramphenicol, and Rifampicin and found susceptible against Gentamycin, Ciprofloxacin, Tetracycline, Norfloxacin, Kanamycin, Azithromycin, Ofloxacin, Vancomycin and Teicoplanin. B.cereus was found resistant against for Ampicillin, Rifampicin, Teicoplanin, and Vancomycin, intermediate against Chloramphenicol, Tetracycline, and found susceptible against Gentamycin, Ciprofloxacin, Norfloxacin, Kanamycin, Azithromycin and Ofloxacin. Methanol extract of Betel leaf was subjected to MIC determination against all the four organisms.

The Methanol extract of Betel leaf was serially diluted to get a decreasing concentration 25.6 to $0.05 \mu \mathrm{l} / \mathrm{ml}$ of nutrient broth. Methanol extract of Betel leaf when seeded with 25 of the broth cultures, exhibited MIC at $0.2 \mu \mathrm{l} / \mathrm{ml}$ for E. coli, $3.2 \mu \mathrm{l} / \mathrm{ml}$ for $B$. cereus, $12.8 \mu \mathrm{l} / \mathrm{ml}$ for $P$. aeruginosa, 0.1 $\mu \mathrm{l} / \mathrm{ml}$ for S. typhi.

The tubes that were incubated for MIC were taken and from each concentration a loop full of test cultures were taken out and streaked on pre-solified nutrient agar. The least concentration at which no visible growth was 
observed in the Nutrient agar plates was considered as MBC. The exhibited MBC at $0.4 \mu \mathrm{l} / \mathrm{ml}$ for E. coli, $3.2 \mu \mathrm{l} / \mathrm{ml}$ for B. cereus, $12.2 \mu \mathrm{l} / \mathrm{ml}$ for P. aeruginosa, $0.2 \mu \mathrm{l} / \mathrm{ml}$ for $S$. typhi. The Betel Leaf possesses many beneficial bioactivities, and its extract from betel leaves has a great potential to be used in developing commercial products.

Due to the numerous benefits. The Methanol extract of Betel leaf in the future can be employed effectively to treat the hospital and community acquired infections caused by $E$. coli, B. cereus, $P$. aeruginosa, and $S$. typhi.

\section{References}

Amonkar, A. J. and Nagabhushan, M. 1986. Hydroxychavicol: A new phenolic antimutagen from betel leaf. Journal

Food and Chemical Toxicology, 24(4): 1321-1324.

Arambewela, D. 2005. Investigations on Piper betle grown in Sri Lanka. International Journal Pharmacognosy Review, 5(10):159-163.

Ali, I. 2010. In vitro antifungal activity of hydroxychavicol isolated from Piper betle L. Journal of Annals of Clinical Microbiology and Antimicrobials, 9(1):702-706.

Aznita, H. 2011. Determination of the percentage inhibition of diameter growth (PIDG) of Piper betle crude aqueous extract against oral Candida species. Journal of medicinal plant research, 5(6):878-884.

Abdu, M., and Kachallah, K. G. 2018. Antibiotic susceptibility patterns of Uropathogenic Escherichia coli among patients with urinary tract infections in a tertiary care hospital in Maiduguri, North Eastern, Nigeria. Journal of Bioscience and Biotechnology Discovery, 6(3): 14-24.

Bauer, A. W., Kirby, W. M. M. 1966.
Antibiotic Susceptibility testing by a standardized single disk method. The American Journal of Clinical Pathology, 4(45): 493-496.

Chakraborty, D., and Shah, B. 2011. Antimicrobial, antioxidative and antihemolytic activity of piper betel leaf extracts, International Journal of Pharmacy and Pharmaceutical Sciences, 3(3):192-199.

Dasgupta, K., and De, G. 2004. Antioxidant activity of Piper betel L. Leaf extract in vitro. Journal of Food Chemistry, 88(2): 219-224.

Hoque, M. 2011. Antibacterial Activity of Ethanol Extract of Betel Leaf (Piper betle L.) Against Some Food Borne Pathogens. Bangladesh Journal of microbiology, 28(2):301-307.

Jesonbabu, G. K. 2015. In Vitro Antimicrobial Potentialities of Chloroform Extracts of Ethanomedicinal Plant Against Clinically Isolated Human Pathogens). International Journal of Pharmacy and Pharmaceutical Sciences, 4(3): 624626.

Kumar, A. 2010. Antibacterial activity and Quantitative Determination of Protein From Leaf of Datura Stramonium and Piper betle plants. Pharmacophore Journal, 1(3): 184-195.

Kaveti, B. 2011. Antibacterial Activity Of Piper Betel Leaves. International Journal of Pharmacy Teaching \& Practices, 2(3):129-132.

Khan, J.A., and Kumar, N. (2011). Evaluation of antibacterial properties of extracts of piper betel leaf. Journal of pharmaceutical and biomedical sciences (JPBMS), 11(11): 212-215.

Mohammad, A. 2015. Prevalence and Antibiotic Susceptibility Pattern of $E$. coli Isolated from Urinary Tract Infection in Patients with Renal Failure Disease and Renal Transplant 
Recipients. Tropical Journal of Pharmaceutical Research, 14(4): 649653.

Nagori, K., Singh, M. K., Alexander, A., Kumar, T., Dewangan, D., Badwaik, H. 2011. Piper betle L.: A review on its ethnobotany, phytochemistry, pharmacological profile and profiling by new hyphenated technique DARTMS (Direct Analysis in Real Time Mass Spectrometry). Journal of Pharmacy Research, 4(9): 2991-2997.

Nerurkar, A. 2012. Bacterial pathogens in urinary tract infection and antibiotic susceptibility pattern. Journal of Pharmaceutical and Biomedical Sciences, 21(12): 212-224.
Olayemi A. B. and Opaleye, F. I. 1999. Antibiotic Resistance Among Coli form Bacteria Isolated from Hospital and Urban Waste Waters. World Journal of Microbiology and Biotechnology, 6(3): 285-288.

Panse, V. G. and Sukhatme, P. V. 1967. Statistical methods for agriculture workere. Indian council of agriculture research publication, New Delhi, 1(4): 357-358.

Sangeetha, K. 2014. Antibiotic resistance pattern of Escherichia coli causing urinary tract infection with an emphasis on fluoroquinolone resistance. Global Journal of Medicine and Public Health, 3(1):227-230.

\section{How to cite this article:}

Ayiman Abdullah Ali Almahdi and Yashab Kumar. 2019. Comparative Study of Antimicrobial Activity of Betel leaf Extract and Antibiotics against Selected Bacterial Pathogens. Int.J.Curr.Microbiol.App.Sci. 8(03): 2009-2019. doi: https://doi.org/10.20546/ijcmas.2019.803.239 